\title{
Autologous human serum for cell culture avoids the implantation of cardioverter-defibrillators in cellular cardiomyoplasty
}

\author{
Juan C. Chachques, MD, $\mathrm{PhD}^{*}$, a Jesus Herreros $\mathrm{MD}^{\mathrm{b}}$, Jorge Trainini $\mathrm{MD}^{\mathrm{c}}$, \\ Alberto Juffe $\mathrm{MD}^{\mathrm{d}}$, Esther Rendal $\mathrm{PhD}^{\mathrm{d}}$, Felipe Prosper $\mathrm{MD}^{\mathrm{b}}$, Jorge Genovese $\mathrm{MD}^{\mathrm{c}}$ \\ ${ }^{a}$ Pompidou Hospital, University of Paris, France \\ ${ }^{b}$ University of Navarra, Spain \\ ${ }^{c}$ Peron Hospital, Avellaneda, Argentina \\ ${ }^{d}$ Canalejo Hospital, Coruna, Spain
}

\begin{abstract}
Background: Current clinical experience with cellular cardiomyoplasty (using serum bovine-cultivated myoblasts) has demonstrated significant malignant ventricular arrhythmias and sudden deaths in patients. In some ongoing clinical trials the implantation of cardioverterdefibrillator is mandatory. We have hypothesized that contact of human cells with fetal bovine serum results after 3-week fixation of animal proteins on the cell surface, representing an antigenic substrate for immunological and inflammatory adverse events.

Methods and Results: Autologous myoblasts were transplanted into infarcted LV in 20 patients ( $90 \%$ males, mean age $62 \pm 8$ years). Cells were cultivated in a complete human medium during 3 weeks, using the patients' own serum obtained from a blood sample or from plasmapheresis. Injections were performed during CABG $(2.1 \mathrm{grafts} / \mathrm{pt})$.

All patients had an uneventful recovery. At a mean follow-up of $14 \pm 5$ months without mortality, no malignant cardiac arrhythmias are reported. $\mathrm{LV}$ ejection fraction improved from $28 \pm 3 \%$ to $52 \pm 4.7 \%(p=0.03)$, and regional wall motion score index (WMSI) from 3.1 to $1.4(p=0.04)$ in the cell-treated segments. Myocardial viability tests showed areas of regeneration. Patients moved from mean NYHA class 2.5 to class 1.2 .

Conclusions: A total autologous cell culture procedure was used in cellular cardiomyoplasty reducing the risk of arrhythmia. Human-autologous-serum cell expansion avoids the risk of prion, viral or zoonoses contamination. Since patients treated with noncultivated bone marrow cells are free of arrhythmia, the bovine-culture medium seems to be responsible for this complication. Cellular cardiomyoplasty may be efficient to avoid progression of ventricular remodeling and subsequent heart failure in ischemic heart disease. (C) 2004 Published by Elsevier B.V. All rights reserved.
\end{abstract}

Keywords: Heart failure; Myocardial infarction; Myocardial regeneration; Cellular cardiomyoplasty

\section{Introduction}

Cell-based myocardial regenerative therapy (i.e. cellular cardiomyoplasty) is undergoing experimental and clinical trials in order to limit the consequences of decreased contractile function and compliance of damaged ventricles following myocardial infarction. This biological approach is particularly attractive due to the potential for myocardial regeneration with a variety of myogenic and angiogenic cell types: skeletal myoblasts, bone-marrow-derived mesenchymal stem cells, circulating blood-derived progenitor cells, smooth muscle cells, vascular endothelial cells, and embryonic stem cells [1-5]. Cellular cardiomyoplasty using autologous skeletal myoblasts or bone marrow cells has been

\footnotetext{
* Corresponding author. Correspondence address: Department of Cardiovascular Surgery, Pompidou Hospital, 20 rue Leblanc, 75015 Paris, France. Tel.:+33-(1)-43959359; fax: +33-(1)-40728608;

E-mail address: j.chachques@brs.ap-hop-paris.fr
}

performed worldwide in more than 200 patients. Inclusion criteria consist of adult patients with a low ejection fraction, akinetic, non-viable post-infarction scar.

Current clinical experience with cellular cardiomyoplasty (using serum bovine-cultivated myoblasts) has demonstrated significant malignant ventricular arrhythmias and sudden deaths in patients. In some ongoing clinical trials the implantation of cardioverter-defibrillator is becoming mandatory [6-7]. Since patients treated with non-cultivated bone marrow cells are free of arrhythmia, we have hypothesized that contact of human cells with fetal bovine serum results after 3 weeks in fixation of animal proteins on the cell surface, representing an antigenic substrate for immunological and inffammatory adverse events. At Duke University (USA), in a rabbit infarct model treated with autologous myoblast transplantation, erratic and aggressive ventricular ectopy and lethal bradycardia were observed after cell implantation; the cells had been cultivated in horse serum [8]. In an attempt to 
repair damaged heart muscle and to improve cardiac function, we have transplanted autologous muscle cells (myoblasts cultivated in autologous human serum) directly into infarcted left ventricular areas in 20 cases.

\section{Clinical study}

\subsection{Patients}

Since December 2001, cellular cardiomyoplasty procedures have been performed in 20 patients ( $90 \%$ males), mean age $62 \pm 8$ years. Patients were in mean NYHA FC 2.5 presenting with impaired LV function (mean radionuclide ejection fraction $28 \pm 3 \%$ ), LV wall post-ischemic scars (akinetic and metabolically nonviable), and surgical indication for $\mathrm{CABG}$ in remote, viable and ischemic areas. The procedure was approved by the institutional review board, and informed written consent was obtained from each patient before the procedure.

\subsection{Muscle biopsy and cell culture techniques}

Before initiating the ex-vivo cell culture procedures, the following "virus free tests" have been performed: anti human immunodeficiency virus (HIV), anti hepatitis B and $\mathrm{C}$ virus (HBV, HCV), IgM anti cytomegalovirus (CMV), HbsAG, and human T-cell leukemiavirus.

\section{Skeletal muscle biopsy}

Three weeks prior to cellular cardiomyoplasty procedure, a biopsy sample of the thigh vastus lateralis was taken through a $5-\mathrm{cm}$ incision under local anesthesia. A $2-3 \mathrm{~cm}^{3}$ skeletal muscle sample $(8-15 \mathrm{~g})$ was explanted under sterile conditions. Immediate fragmentation of the muscle with scissors was performed and the sample was immerged in complete culture medium or in PBS (phosphate buffer solution, GIBCO) and kept at $4^{\circ} \mathrm{C}$.

\section{Cell isolation and in vitro expansion}

All manipulations were performed in a laminar flow hood using an aseptic technique. The explanted skeletal muscle pieces were washed in PBS. Adipose tissue and fascia were removed and the muscle was carefully minced with scissors. The muscle fragments were washed again in PBS until the supernatant remained clear. Tissue dissociation was obtained by two consecutive enzymatic treatments: first, cells were incubated with collagenase IA $(1.5 \mathrm{mg} / \mathrm{ml} / \mathrm{gram}$ of tissue) (Sigma Chemical $\mathrm{Co}$ ) and left in the incubator for 1 hour, followed by mechanical dissociation obtained by shaking the tube every ten minutes. A second incubation with $0.25 \%$ trypsin $1 \mathrm{x}$ EDTA ( $2 \mathrm{ml}$, GIBCO BRL) was then performed for 20 minutes. Cells were then washed (10 minutes at $300 \mathrm{~g}$ ) and enzymatic reaction stopped by adding $1 \mathrm{ml}$ of the patient's own serum. Filtration through a $40 \mu \mathrm{m}$ sieve (Falcon cell strainer nylon, Becton Dickinson, Franklin Lakes, NJ) was then performed and a second enzymatic digestion was conducted on the remaining fragments which eventually rest on the sieve.
Cell pellets were resuspended in fresh complete culture medium: 79\% HAM-F12 medium, 1\% penicillin/ streptomycin (GIBCO) and 20\% patient's serum obtained from blood sample (6 patients) or from plasmapheresis (14 patients). This plasma exchange procedure was performed the day before the muscle biopsy using heparin as anticoagulant, coagulation proteins were then eliminated by neutralization of heparin with protamine sulphate. The mean volume of autologous serum obtained for cell cultures was $1450 \pm 220 \mathrm{ml}$. After testing for bacterial contamination, aliquots of $50 \mathrm{ml}$ were cryopreserved until usage.

The cells were plated in culture flasks and incubated during 3 weeks at $37^{\circ} \mathrm{C}$ in a humidified atmosphere containing $5 \% \mathrm{CO}^{2}$. After a $2-3$ day incubation time, the medium was changed, eliminating dead cells and blood cells in the supernatant, then fresh complete culture medium was added. Passaging of the cultures (1:5 split) was carried out at subconfluency ( $50 \%$ of confluency) to avoid myotube formation. Cells were harvested by trypsinization $(2 \mathrm{ml}$ of $0.25 \%$ trypsin-EDTA in each flask for 1 to 5 minutes in the incubator).

\section{Fibroblast removal from myoblast culture}

Cells underwent a pre-plating step on the first passage to deplete fibroblast from the culture. Pre-plating is based on the quicker attachment of fibroblasts compared to myoblasts. On the day of transplantation, cells were harvested and washed in the injection medium (human albumin $0.5 \%+$ complete culture medium) and kept in ice before implantation. A sample was performed to assess final myoblast rate, by flow cytometry test: percentage of myoblasts CD56-positive (Miltenyi Biotec, Germany), and desmin antibody positive cells (Sigma-Aldrich, France). Cell concentration and viability were determined with Trypan blue using a Malassez cytometer or FACS (flow cytometry). Sterility of cell culture was also assessed before implantation (Gram tests). At the moment of implantation, the rate of myoblasts was $78 \pm 5 \%$ and the rate of viable cells was $95 \pm 3 \%$. Density of implanted cells was 50-70 million cells per $\mathrm{ml}$.

\section{3. $C A B G$ and cellular cardiomyoplasty}

Cells were in-vitro expanded in $17 \pm 4$ days up to $300 \pm 20$ millions. Injections were performed during CABG surgery via sternotomy ( 2.1 grafts $/ \mathrm{pt})$. Six procedures were performed off-pump and 14 under cardiopulmonary bypass. At the end of CABGs, cell implantation was performed into wellexposed $\mathrm{LV}$ ischemic areas, permitting $12 \pm 3$ injection points within and principally around the infarct, with a $25 \mathrm{G} \times 40 \mathrm{~mm}$ retrobulbar ophthalmic needle. Our approach consisted in performing the main implantation in the peri-infarct area ( $70 \%$ of cells), since residual irrigation and collateral myocardial revascularization in this intermediate area allows for a better survival of the implanted cells. The remaining $30 \%$ of cells were implanted in the central portion of the scar. 


\subsection{Postoperative management and clinical follow-up}

All patients received oral amiodarone $(200 \mathrm{mg} /$ day) as antiarrhythmic drug, starting 1 week before surgery and up to the third postoperative month. Following surgery the patient's cardiac rhythm was monitored with continuous inhospital telemetry. After discharge, ECG-Holter monitoring was performed at 1,2 and 3 months. Ventricular function was evaluated by echocardiography (including dobutamine stress tests and color kinesis) and radionuclide ventriculography (MIBI gated SPECT). Myocardial viability was assessed with fluorodeoxyglucose (18FDG) positron emission tomography (PET).

\section{Results}

The technique used for "in vitro" cell expansion yielded over 300 million cells in 3 weeks, of which more than $70 \%$ were myoblasts. Cell viability at the moment of injection was greater than $90 \%$. All patients had an uneventful recovery and discharged from the ICU $3 \pm 2.2$ days following surgery. Patients were discharged from the hospital at $12 \pm 3$ postoperative days. Patients moved from mean heart failure class 2.5 to mean NYHA class 1.2. At a mean follow-up of $14 \pm 5$ months without mortality, no malignant cardiac arrhythmias were reported. The number of premature ventricular beats $/ 24$ hours was $167 \pm 24$ (pre-op), $28 \pm 9$ (at discharge), $56 \pm 13$ (at 1 month) and $10 \pm 4$ (at 3 months). The postoperative reduction of the number of premature ventricular beats could be related to amiodarone administration and with surgical revascularization (Fig. 1).

Radionuclide ventriculography showed improvements of $\mathrm{LV}$ ejection fraction (from $28 \pm 3 \%$ to $52 \pm 4.7 \%, p=0.03$ ). Echocardiographic studies of cell-treated segments demonstrated improvement in regional wall motion score index (WMSI) from $3.1 \pm 0.2$ to $1.4 \pm 0.9(p=0.04)$. Dobutamine stress echocardiography showed improvement in the cell-treated area (Fig. 2). Echocardiography using colorkinesis software showed improvement in treated areas (Fig. 3). Myocardial viability tests showed areas of regeneration, the mean $18 \mathrm{FDG}$ PET increased from pre-operative $0.158 \pm 0.026$ to $0.270 \pm 0.008 \mu \mathrm{mol} \mathrm{g}^{-1} \mathrm{~min}^{-1}$ at 3 months $(p=0.012)$, the main increased uptake was observed in infarcted areas (Fig. 4).

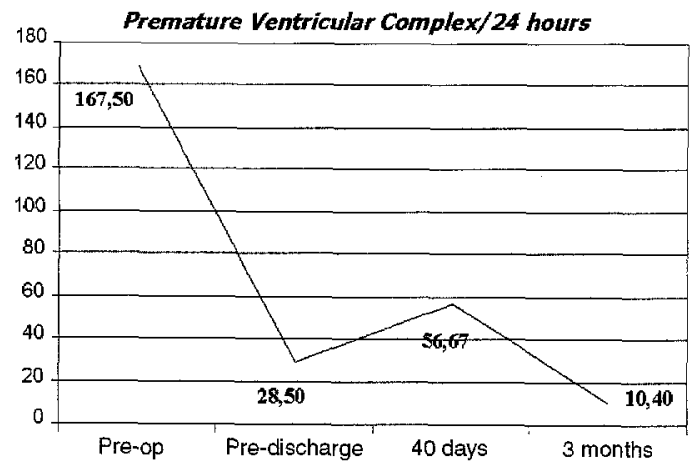

Fig. 1. ECG-Holter monitoring following cellular cardiomyoplasty.
Dobutamine stress echocardiography

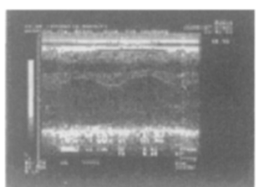

Pre-implant

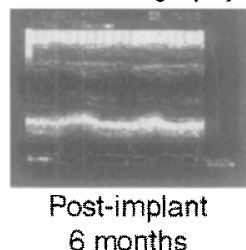

6 months
Fig. 2. Dobutamine stress echocardiography showing improvement in the cell treated LV posterior wall (6-month follow-up).

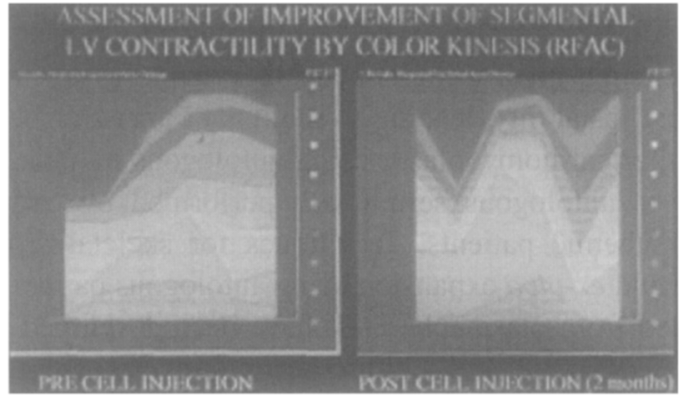

Fig. 3. Echocardiography using color-kinesis software 2 months after myoblast implantation, showing LV motion improvement in treated areas. [See p. S72 for color illustration.]

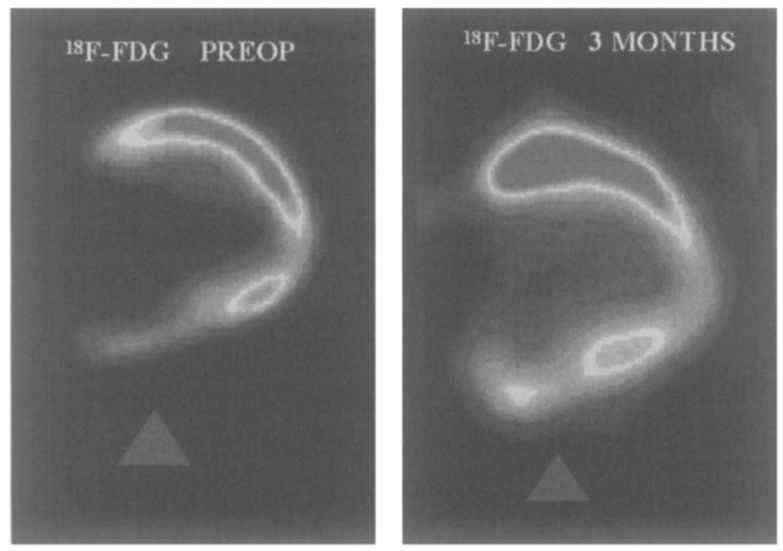

Fig. 4. Myocardial viability test (18FDG PET) showing regeneration of infarcted areas (arrow) after cellular cardiomyoplasty (3-month follow-up). [See p. S72 for color illustration.]

The best functional results have been obtained in 6 patients presenting a heterogeneous infarct area (patchy appearance), i.e. a mixture of viable myocardial tissue and multiple small scars. Therefore a "vascularized fibrosis" seems to be a better indication for cellular CMP than a "non-vascularized" postinfarct scar.

The association of CABGs with cellular cardiomyoplasty was imposed by the institutional review board and thus the individual contribution of each procedure cannot be clearly elucidated at this stage of our clinical trial.

\section{Discussion}

The goal of cellular cardiomyoplasty is to regenerate the myocardium in ischemic and non-ischemic cardiomyopathies. This approach can be performed using surgical 
or interventional cardiology procedures [9-13]. In current clinical trials, the number of surgical cell implantations seems to be equivalent to those of percutaneous catheterbased procedures, and the number of patients treated with autologous skeletal myoblasts was equivalent to those treated with bone marrow cells. However, there is a tendency to use bone marrow cells for myocardial regeneration since this approach avoids the 3-week cell culture procedure and the risk of ventricular arrhythmias and sudden death observed after transplantation of skeletal myoblasts. Directly injecting skeletal-myoblasts-derived cells cultivated with bovine serum into ischemic myocardium seems to provide a substrate for electrical instability, leading to malignant arrhythmia.

Cellular cardiomyoplasty using autologous myoblasts cultivated in autologous serum was performed by our group in 20 ischemic patients. Techniques for skeletal-myoblasts culture and ex-vivo expansion using autologous patient serum (obtained from plasmapheresis) have been developed by our group. Traditional cell-culture techniques involve the use of fetal bovine serum for cell growth. Contact of human cells with fetal bovine serum results after 3 weeks in fixation of animal proteins on the cell surface, representing an antigenic substrate for immunological adverse events. After cell implantation an inflammatory reaction may occur, creating fibrosis; some human autopsies showed this fibrosis [14-17]. Malignant ventricular arrhythmias and sudden deaths have been reported following serum bovine-cultivated cell therapy, and in many cases this complication required the implantation of cardioverter-defibrillators. Additional and important benefits of human-autologous-serum cell culture is that it can be performed without risk of prion, viral or zoonose contamination.

The mechanism by which implanted cells improve heart function remains controversial. Cell-based myogenic therapy seems to reduce the size and fibrosis of infarct scars, limit post-ischemic remodelling, and restore regional myocardial contractility in patients following non-massive myocardial infarction. Several factors contribute directly or indirectly to the structural and functional benefits afforded by muscle-cell transplantation. Cells grafted in the infarcted area contribute to decrease scar thinning and chamber dilatation (scaffolding effect). Muscle-cell implantation increases regional elasticity and alters extracellular matrix preventing ventricular remodeling [18-21]. The regeneration of the collagen matrix can be due to the partial reconstitution of the interstitial collagen, since during the culture of myoblasts approximately $20-30 \%$ of fibroblasts remain in mixture with muscle cells. Following implantation, these fibroblasts could probably contribute to the regeneration of the myocardial collagen matrix. The mechanism explaining the transmission and propagation of electromechanical impulses from the native myocardium to the engrafted cells has not been elucidated. Response to a mechanical stimulus exerted by surrounding cardiomyocytes could be responsible for inducing this contraction, since the grafted myoblasts are dencrvated and gap junctions with the native myocardium have not been demonstrated $[20,22]$.
While various donor cells have been studied to induce myogenesis after myocardial infarction, recently interest has arisen in promoting cardiac angiogenesis by the transplantation of vascular endothelial cells or endothelial progenitor cells (directly removed or mobilized from bone marrow) $[4,5]$. This approach retains an important potential as an adjunct to myogenic cellular transplantation in inducing angiogenesis in injured myocardium, because the mortality of muscular cells after implantation in high-fibrotic infarcted myocardium seems to be high due to the limited supply of oxygen and nutrients within the scar. Thus, cell-based angiogenic therapy is in strong development for myocardial and limb ischemia due to the instability and adverse response to transfection vectors of angiogenic gene therapy, and the limitations of growth-factor protein-based therapy, which present risks of systemic effects (inducing problematic angiogenesis in the retina, intimal arterial hyperplasia with development of atheromatous plaque, and potentiation of growth and metastasis of occult tumors).

In conclusion, cell-based myogenic therapy seems to reduce the size and fibrosis of infarct scars and to restore regional myocardial contractility in patients following nonmassive myocardial infarction. Current results allow to recommend cellular cardiomyoplasty for myocardial regeneration in cases of moderate cardiac insufficiency (i.e., not for severe cardiac insufficiency), in order to avoid the progression of ventricular remodeling and heart failure. Periodically repeated cell-injection procedures could be necessary to improve myocardial regeneration and function; this staged delivery approach should be facilitated by recently developed percutaneous systems, e.g., the "Cell-Fix" catheter-electrode for diagnostics and injection in cardiology treatments [23]. Autologous serum for cell cultures seems to play a role to prevent malignant ventricular arrhythmias and sudden death following skeletal myoblast implantation [24-26]. New experimental and clinical studies should be encouraged.

\section{References}

[1] Chachques JC, Acar C, Herreros J, et al. Cellular cardiomyoplasty: clinical application. Ann Thorac Surg 2004;77:1121-30.

[2] Reffelmann T, Kloner R $\Lambda$. Cellular cardiomyoplasty: cardiomyocytes, skeletal myoblasts, or stem cells for regenerating myocardium and treatment of heart failure? Cardiovasc Res 2003;58:358-68.

[3] Haider HK, Tan AC, Aziz S, Chachques JC, Sim EK. Myoblast transplantation for cardiac repair: A clinical perspective. Mol Ther 2004;9:14-23.

[4] Chiu RCJ. Therapeutic cardiac angiogenesis and myogenesis: the promises and challenges on a new frontier. J Thorac Cardiovasc Surg 2001;122:851-2.

[5] Norol F, Merlet P, Isnard R, et al. Influence of mobilized stem cells on myocardial infarct repair in a nonhuman primate model. Blood 2003;102:4361-8.

[6] Menasche P, Hagege AA, Vilquin JT, et al. Autologous skeletal myoblast transplantation for severe postinfarction left ventricular dysfunction. J Am Coll Cardiol. 2003;41:1078-83.

[7] Smits PC, van Geuns RJ, Poldermans D, et al. Catheter-based intramyocardial injection of autologous skeletal myoblasts as a primary 
treatment of ischemic heart failure: clinical experience with six-month follow-up. J $\Lambda \mathrm{m}$ Coll Cardiol 2003;42:2063-9.

[8] Soliman AM, Taylor DA, Thompson RB, et al. Assessment of electrical instability after autologous myoblast transplantation in a rabbit infarct model. Circulation 2003;108(Suppl IV):547.

[9] Chachques JC, Cattadori B, Herreros J, et al. Treatment of heart failure with autologous skclctal myoblasts. Hcrz 2002;27:570-8.

[10] Thompson CA, Nasseri BA, Makower J, et al. Percutaneous transvenous cellular cardiomyoplasty. A novel nonsurgical approach for myocardial cell transplantation. J Am Coll Cardiol 2003;41:1964-71.

[11] Tse HF, Kwong YL, Chan JK, et al. : Angiogenesis in ischaemic myocardium by intramyocardial autologous bone marrow mononuclear cell implantation. Lancet 2003;361:47-9.

[12] Assmus B, Schächinger V, Teupe $C$, et al. Transplantation of progenitor cells and regeneration enhancement in acute myocardial infarction (TOPCARE-AMI). Circulation 2002;106:3009-17.

[13] Perin EC, Dohmann HF, Borojevic R, et al. 'Iransendocardial, autologous bone marrow cell transplantation for severe, chronic ischemic heart failure. Circulation 2003;107:2294-302.

[14] Hagege AA, Carrion C, Menasche $P$, et al. Viability and differentiation of autologous skeletal myoblast grafts in ischaemic cardiomyopathy. Lancet 2003;361:491-2.

[15] Pagani FD, DerSimonian H, Zawadzka A, et al. Autologous skeletal myoblasts transplanted to ischemia-damaged myocardium in humans. Histological analysis of cell survival and differentiation. J Am Coll Cardiol 2003;41:879-88.

[16] Leobon B, Garcin I, Menasche P, et al. Myoblasts transplanted into rat infarcted myocardium are functionally isolated from their host. Proc Natl Acad Sci USA 2003;100:7808-11.
[17] Minami E, Reinecke H, Murry CE. Skeletal muscle meets cardiac muscle: Friends or foes? J Am Coll Cardiol 2003;41:1084-6.

[18] Stamm C, Westphal B, Kleine HD, et al. Autologous bone-marrow stem-cell transplantation for myocardial regeneration. Lancet. 2003; 361:45-6.

[19] Strauer BE, Brehm M, Zeus $T$, et al. Repair of infarcted myocardium by autologous intracoronary mononuclear bone marrow cell transplantation in humans. Circulation 2002;106:1913-8.

[20] Rajnoch C, Chachques IC, Berrebi A, et al. Cellular therapy reverses myocardial dysfunction. J Thorac Cardiovasc Surg 2001;121:871-8.

[21] Chedrawy EG, Wang JS, Nguyen DM, et al. Incorporation and integration of implanted myogenic and stem cells into native myocardial fibers: anatomic basis for functional improvements. J Thorac Cardiovasc Surg 2002;124:584-90.

[22] Smythe GM, Hodgetts SI, Grounds MD. Problems and solutions in myoblast transfer therapy. J Cell Mol Med 2001;5:33-47.

[23] Chachques JC, Herreros J, Vega 1. Catheter "Cell-Fix" for diagnostic and injection in cardiology treatments. French Patent 03 13719, 2003 (International PCT Application).

[24] Herreros J, Prosper F, Perez A, et al. Autologous intramyocardial injection of cultured skeletal muscle-derived stem cells in patients with non-acute myocardial infarction. Eur Heart J 2003;24:2012-20.

[25] Trainini JC, Lago N, De Paz J, et al. Myoblast transplantation for myocardial repair: a clinical case. J Heart Lung Transplant 2004;23: $503-5$.

[26] Chachques JC, Shafy A, Duarte F, et al. From dynamic to cellular cardiomyoplasty. J Card Surg 2002;17:194-200. 